\title{
CONVERSATION GROUP
}

\section{Top Concerns of Technical Services Staff}

Notes taken by Heather Hicks, Technical Services Librarian, Southwestern Baptist Theological Seminary

About twenty interested individuals met on Tuesday evening, June 11,2019 , for the regular preconference technical services conversation group. In their normal manner of freewheeling conversations, the attendees mentioned and discussed a variety of topics. The following is a summary of some of the topics and thoughts expressed.

Topic: Summaries in MARC field 520:

- Leslie - Hyperbolic summaries for books, not representative of content but for selling; summaries that are ethically compromising. Do we keep, do we delete? Some keep if fairly representative, some delete.

Topic: Ebook records (The problem of bad cataloging records and how to handle these challenges best):

- Catalog/cataloging ebooks - poor records. Catalogers do not have enough time to update the master records, which defeats the purpose of WMS and moves the problem to the next cataloger, defeating cooperative cataloging.

- Records come with generic, unhelpful subject headings like "Religion” for all religious books. Need to fix before import. Update master record? What to do? Any best practices? Most update for local use unless the batch is too large. 
- Can we keep up with OCLC adding content? Cooperative cataloging? Speed is an issue (perhaps number of catalogers as well?)

- Contents notes in ebooks - Are they even needed, since the resource is so easily accessed to find content; or can we hyperlink them directly, combining the two?

- Is there a good forum or a proper forum for discussing ebook issues with OCLC? Public lists are more responsive than private channels.

- Leslie recommends OCLC AskQC office hours - a good place to present dissatisfaction with OCLC on broader metadata issues. Sessions have an appointed topic with option to introduce other topics.

- Redundant title results in machine-generated table of contents 505 notes - how does this affect our search algorithms? Does it hinder, does it help?

- Phil - put in keywords for discovery or leave them out for clean search (access vs. precision). At what point is retrieval compromised? Which is better for the user? Access or clean system? Perhaps a good balance.

Topic: OCLC:

- No credit for OCLC work.

- Lots of money, and quality is not worth it.

- OCLC competition? State cooperation: will state consortia provide what OCLC is failing to do? Again, this breaks up the global unit of knowledge, defeating the purpose of cooperative cataloging.

Topic: New RDA Toolkit/LRM - too far in advance to discuss much now:

- Moving to the New RDA/LRM with only digital access. Other libraries don't have the option to access the current rules. No print version. Not equally accessible to all libraries and librarians, not in keeping with the general rules of the library cooperative environment.

- New LRM - makes sense of relationships in a linked-data environment. Combines FRBR/FRAD/FRSAD. 
Topic: Training of catalogers:

- What is being taught to catalogers? Uneducated catalogers are entering the field. Library Science programs are not requiring cataloging classes. Doing information organization. Training what should it be that we do?

- Cataloging as apprenticeship. Documentation is key. Lifelong learning. Do our best to be aware of issues and learn as much as possible.

Topic: "Multiple" subdivisions in authority records:

- Example: Bashfulness \$x Religious aspects \$x Buddhism. These are being put into one string for the linked database.

- Can still use old headings until the new specific subject heading is available and authorized.

- LC/OCLC will update these automatically so wait for them to be updated.

Small pitch for TCB testimonies by Leslie.

Meeting adjourned. 